\title{
Automatic Traffic Control Technologies for Remote Monitoring Of Unmanned Railway Gates
}

\author{
JV Anand, Assistant Professor, \\ ECE Department, \\ PACE Institute of Technology and Science, \\ Ongole, India. \\ Email ID: jvanand87@gmail.com
}

\begin{abstract}
Continuous researches are done to improve technologies for developing effective, economical and productive solutions for preventing fatalities in the railway gates that are unmanned. Several solutions in this research field have been suggested but none of them are sufficiently effective to deploy them at the automated level crossings and fully eradicate human presence. Surveying the current methodologies and the pitfalls in them the paper has developed an efficient and cost effective remote monitoring for unmanned railway gates, enabling automated traffic control technologies and the wireless sensors. The paper scope in developing an automated traffic control in the unmanned railway gates in India.
\end{abstract}

Keywords: Unmanned Railway Gates, Cost Effective Remote Monitoring, Wireless Sensor Networks, GPS and Cloud Computing.

\section{Introduction}

The Indian railways that is considered as one of the world's most enormous paradigm of railways is encompassed with tracks covering area of 115,001 kilometers, taking routes encompassed over an area of 65,809 kilometers and more than twenty three million people are expected to take this mode of transmission. There are certain unavoidable cases where the railway routes are constructed through the rural areas, and the forest areas where much human existence could not be found, and so the railway gates also remains unmanned. But most of the accidents resulting in fatalities are likely to take place only in such places. In these types of railway crossings that lay without any human assistance, both humans and animals from the rural and the forest areas are affected respectively.

There are around 11,001 railway crossing in India that remains as a reason for most of the accidents that occurs in a year. "According to figures collected by activist Sameer Javari under a Right to Information demand, 3, 202 passengers died and 3, 363 were injured last year on the suburban rail network". They are mainly due to the incompetence of road vehicle users in failing to comply with the safeguards set out in the

ISSN: 2582-3825 (online) 
Journal of Electronics and Informatics (2020)

Vol.02/ No. 01

Pages: $30-37$

http://www.irojournals.com/iroei/

DOI: https://doi.org/10.36548/jei.2020.1.004

Motor Vehicles Act when negotiating unmanned level crossings. "Highest deaths in a year occur due to collisions at manned level crossings, according to the Railway budget 2015-16". Though the information gathered seem old the level crossings are still a reason for the $40 \%$ of India's rail accidents.

Rail-related accidents are more severe in terms of frequency and death rate than any other transport accident. Therefore, more effort is required to strengthen railway safety and protection, the five major categorization on the accidents that are associated with the rail way level crossing are, (i) collisions of trains due to improper communication, (ii) derailing of Train, (iii) fire accidents, ( iv ) suicidal attempts, (v) accidents at the railway gates.

The pie- chart displayed below, in figure. 1 is shows the percentage of the types of the accidents taking place in the railways.

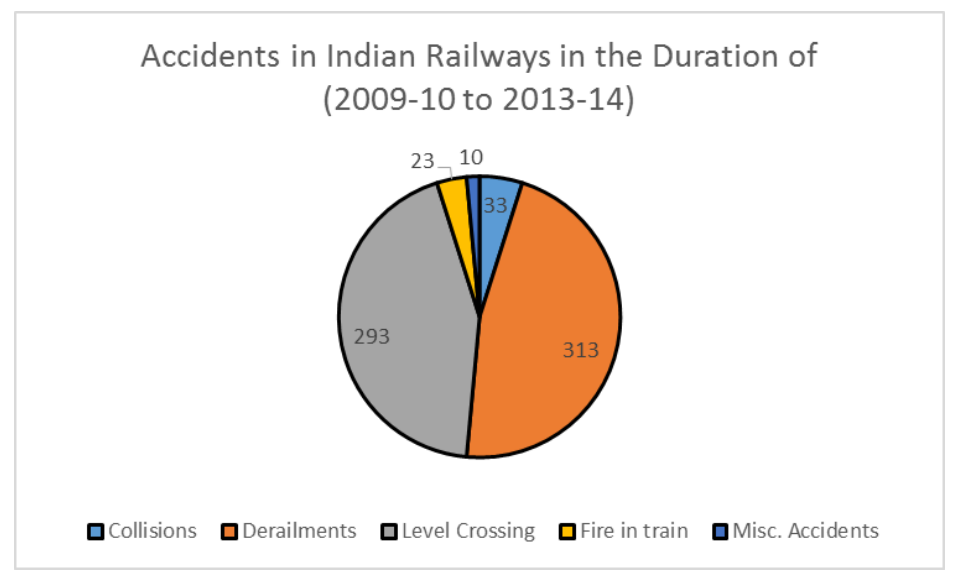

Figure.1 Percentage of Accident Categories

So the paper scopes in developing an unmanned railway gate that operates with reduction in the human intervention, accidents and collision, and finally the duration taken for the operation that is the closing and the opening of the gate, apart from this the developed model also takes care that no humans are trapped into the tract when the level barriers are closed. The key contribution of the paper is as follows

- Developing a gate that is capable of sensing the arrival of train utilizing the "sensors", to regulate the operation of the gates and the traffic signals accordingly.

- Controlling the movement of train on detecting an obstacle, when the gate is closed.

ISSN: 2582-3825 (online) 
Journal of Electronics and Informatics (2020)

Vol.02/ No. 01

Pages: $30-37$

http://www.irojournals.com/iroei/

DOI: https://doi.org/10.36548/jei.2020.1.004

- Receiving and transmitting the details to and from the train using the cloud server and uploading the information's to the cloud server

This automated traffic control technologies of monitoring the unmanned railway gates remotely has been arranged with the literature survey in section 2, proposed design in section 3, results in section 4 and conclusion in section 5 .

\section{Literature Survey}

The accidents usually happen only due to over speed, ignorance or over confidence of the drivers, the accident in the railway level crossing usually happen only either due to the ignorance of the people or the due to people who break the traffic rules. Many times the unexpected calamities happen only as the people rush to their level crossing when the train is too close or intentionally goes to the level crossing to end their life. So it become necessary to develop a system that monitors the movement of the train and report to the level crossing few minutes before the train arrives. Some of the similar existing methods and the techniques adopted in the proposed method from the papers survey are discussed in this section.

Knowing the need for the proper control on the level crossing that are unmanned the Dubey et al [1] in his paper has utilized the wireless sensor networks to develop the automated level crossing, that initiates the operation of the gates on detecting the arrival of the train. This was basically developed to bring down the accident rate that are actually mention in the budget of 2015 [2], Michalík et al [3] performed the "Cooperation of the control logic of the t-shape road intersection and the near railway level crossing."

Tjahjono, et al [4] conducts the "Identification determinant variables of the injury severity crashes at roadrailway level crossing in Indonesia." Pattanaik et al [5] develops a "Decision support model for automated railway level crossing system using fuzzy logic control." To bring down the loss caused due to the accidents in the railway crossing the Sharad, et al [6] devised an automated railway crossing. Laapotti, et al [7] presents the "Comparison of fatal motor vehicle accidents at passive and active railway level crossings in Finland." David et al [8] utilizes the wheel detector to design the "automated railway crossing" Salmon et al [9] conducts the "Beyond the crossing: a cognitive work analysis of rail level crossing systems"

Duraipandian, M et al [10] puts forth the. "Cloud based Internet of Things for smart connected objects." Sivaganesansdzz, D et al [11] devises the "Efficient Routing Protocol with Collision Avoidance in Vehicular Networks." Smys, S et al [12] puts forward an "Autonomous Vehicle Navigation in Communication Challenged Environments-A Simulation Approach." Raj, Jennifer S et al [13] proposed

ISSN: 2582-3825 (online) 
Journal of Electronics and Informatics (2020)

Vol.02/ No. 01

Pages: $30-37$

http://www.irojournals.com/iroei/

DOI: https://doi.org/10.36548/jei.2020.1.004

the automation in green house using the IOT. Manoharan et al [14] performed the "An Improved Safety Algorithm for Artificial Intelligence Enabled Processors in Self Driving Cars." To enhance the safety in the self-driving cars.

\section{Proposed Work}

The methodology utilized in the paper in designing the automated traffic control for the railway gates that are unmanned involves the radio-frequency identification, infrared sensors and the global positioning system. The proffered system is segregated into two phases with the receiver system and the transmitter modules, both the railway crossing as well as the train holds both the transmitting and the receiving module. To get the intimation about the movement and the location of the train.

The Transmitter module is equipped with the tag for the radio frequency identification, an on board unit that intimates the location of the train or the level crossing using the global positioning system, and the controller that receives the continuous movement of the train with the help of the sensor and process the information as well as the aforementioned particulars and regulates the actions that are to be taken. The train as well as the level crossing is located with the GPS transmitter and the receiver as well. The tracks are equipped with the infrared-sensors on the either sides to elude the movement of any object when the train is near by closing the gate on both the sides and detect the trains motion and its proximity. The tags with the radio frequency identification are placed in the train and the tracks to identify the train. The explanation below in table. 1 provides the particulars of the each module used in the proposed design.

\begin{tabular}{|l|l|}
\hline \multicolumn{1}{|c|}{ Modules used } & \multicolumn{1}{c|}{ Descriptions } \\
\hline $\begin{array}{l}\text { GPS- UBLOXNEO } \\
\text { high performance }\end{array}$ & $\begin{array}{l}\text { Sends real Time location and velocity } \\
\text { Tracks train movement } \\
\text { Provides the Geo-coordinates of the } \\
\text { moving train at a set frequency }\end{array}$ \\
\hline $\begin{array}{l}\text { RFID-Reader USB Brand RDL Model } \\
\text { V1.O }\end{array}$ & $\begin{array}{l}\text { Reads the information stored about the } \\
\text { train in he TAG, }\end{array}$ \\
$\begin{array}{l}\text { Automated data collection } \\
\text { Does not require physical sight or } \\
\text { contact between reader/scanner and the } \\
\text { tagged item. }\end{array}$ & \\
$\begin{array}{l}\text { Can be utilized even in unfavorable } \\
\text { conditions }\end{array}$ & \\
\hline $\begin{array}{l}\text { IR-PFR359F } \\
\text { Perform distance calculation function. }\end{array}$ & $\begin{array}{l}\text { situated at about 7-10 km from the level } \\
\text { crossing } \\
\text { Identifies the Speed } \\
\text { Detects train in approaching crossing }\end{array}$ \\
\hline Processors raspberry pi model B & $\begin{array}{l}\text { Does decision making, controls the } \\
\text { output }\end{array}$ \\
\hline Controllers used Arduino MEGA & Does decision making controls the output \\
\hline
\end{tabular}

Table.1 Modules Used in Proposed Design

ISSN: 2582-3825 (online) 
Journal of Electronics and Informatics (2020)

Vol.02/ No. 01

Pages: $30-37$

http://www.irojournals.com/iroei/

DOI: https://doi.org/10.36548/jei.2020.1.004

The proffered strategy was carried out with the as shown in the flowchart below in figure. 2 the fundamental function that significant in the automated traffic control model of the un manned railway gate were (a) the decoding process that is essential to decode the information received by global positioning system (location (loca_train) and velocity (Speed_train)), the radio frequency identifier (Tag_Msg)and the infrared signals (time of interruption (Time interrupt $_{\text {) }}$ )

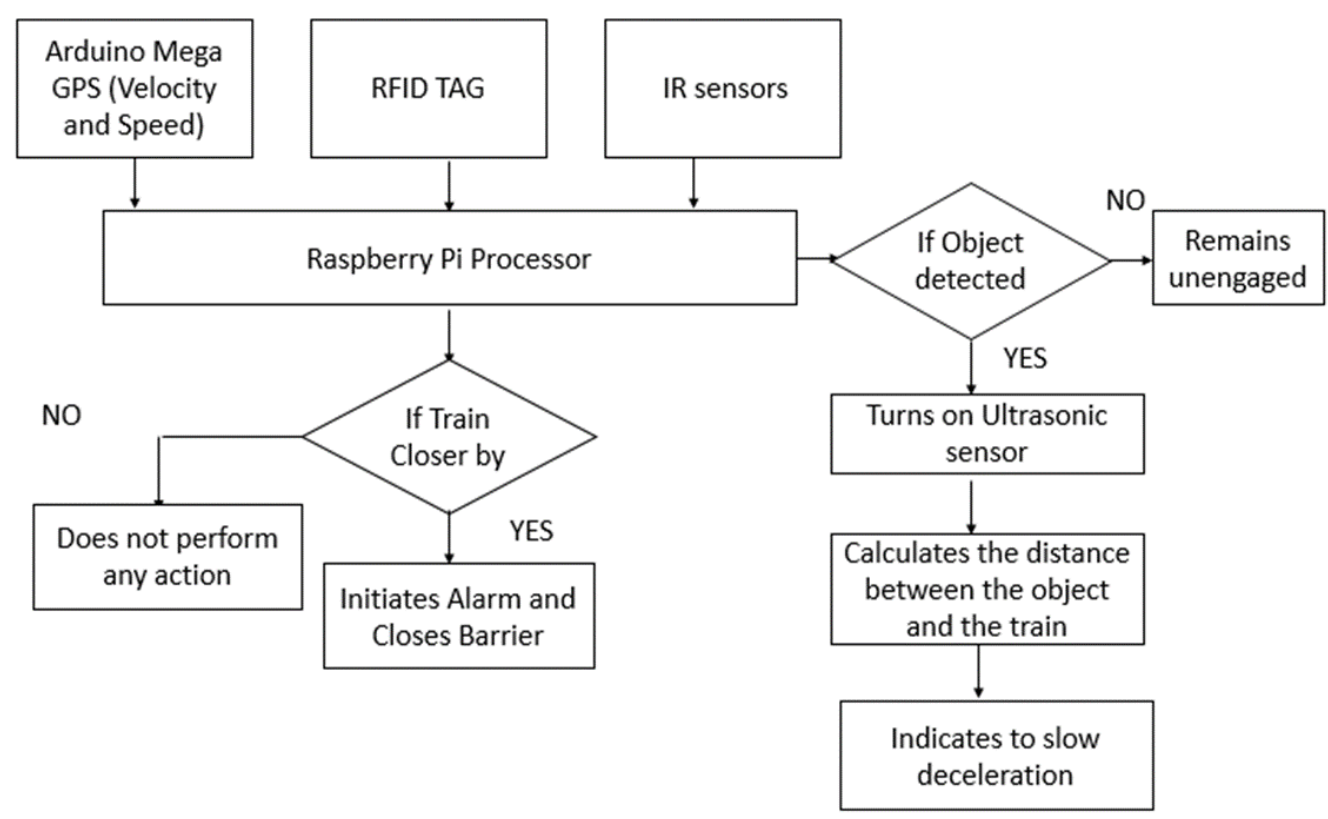

Figure.2 Proposed Flow-Diagram

The inputs are fed into the processor are computed to sort out the velocity, location of the train and intimates this to the receiver module in the "level crossing" if the train is closer to the railway gate using the RF24h transceiver in the Arduino board in the train, the control unit in the level-crossing raises an alarm signal and the barriers are closed with the servo motor that 0 to 90 and vice versa slowly. The processor further signals, when the sensor placed on the roads are interrupted by the vehicles, this signals the train as well as the driver of the vehicle and the ultra-sensor fixed on the front side of train immediately transmits and receives the signals and estimates the distance between the object and the train and given as input to the processor that helps to supply only preferred voltage to the motors with help of the driver board and a minimum breaks are applied in order to prevent inside accidents in the train due to sudden application of breaks. Further the information's about the train next station, its water requirement and other necessities etc are uploaded to the cloud server and intimated to the authorized person, "a client request application running on each individual barrier node, as verified data is passed, a post request is sent to the cloud server which

ISSN: 2582-3825 (online)

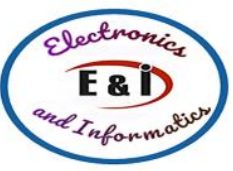


Journal of Electronics and Informatics (2020)

Vol.02/ No. 01

Pages: $30-37$

http://www.irojournals.com/iroei/

DOI: https://doi.org/10.36548/jei.2020.1.004

posts the train information that are stored in immediately to the requested, level crossing" 'the information's from the Arduino board in the train is communicated to the raspberry pi in the barriers over Wi-Fi, the processors are programmed using the python.

\section{Results Evaluation}

The mechanism put forth to properly regulate the unmanned barriers of the rail way crossing was implemented in the python and evaluated utilizing the MATLAB to verify the Processing speed and the time required to processes the information through the proposed model. The figure. 3 below shows the input fed to the Processor using the "GPS, RFID and the IR"

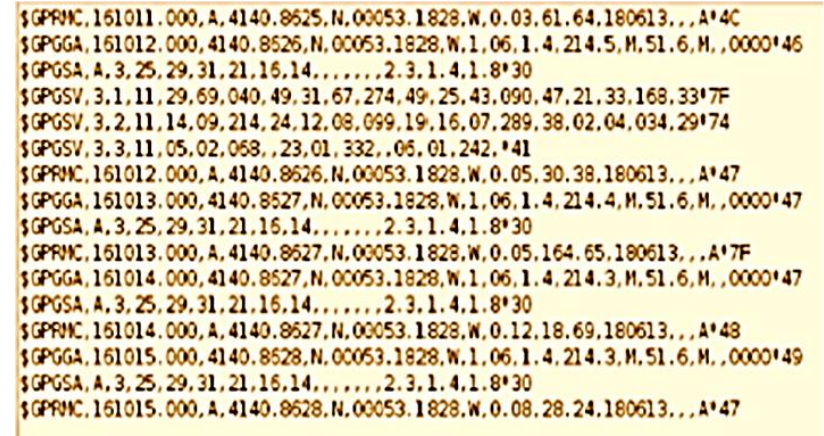

(a)

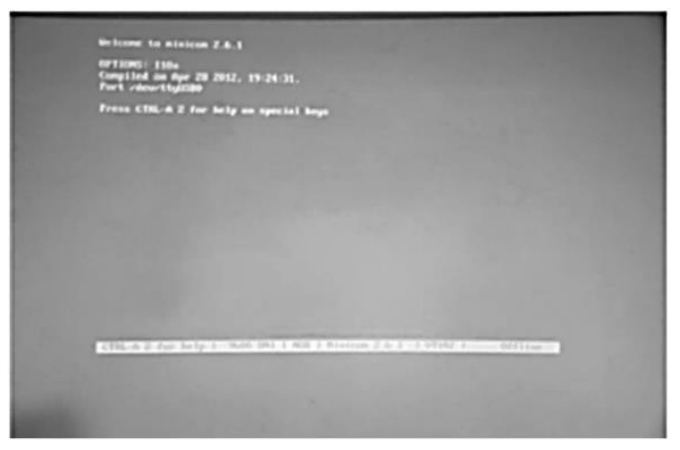

(b)

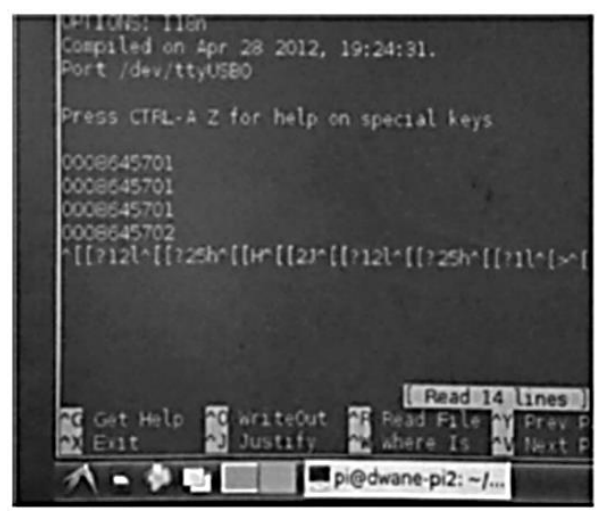

(c)

Figure.3 Input of "GPS (a)", "RFID (b)", "IR(c)" 
Journal of Electronics and Informatics (2020)

Vol.02/ No. 01

Pages: $30-37$

http://www.irojournals.com/iroei/

DOI: https://doi.org/10.36548/jei.2020.1.004

Based on the inputs received the barriers and the alarms in the railway crossing are activated and the accidents are avoided, the results below in in figure. 4 shows the time consumption the energy utilization and the cost incurred by the proposed model against the conventional model that use the telephonic intimations and the manual labor.

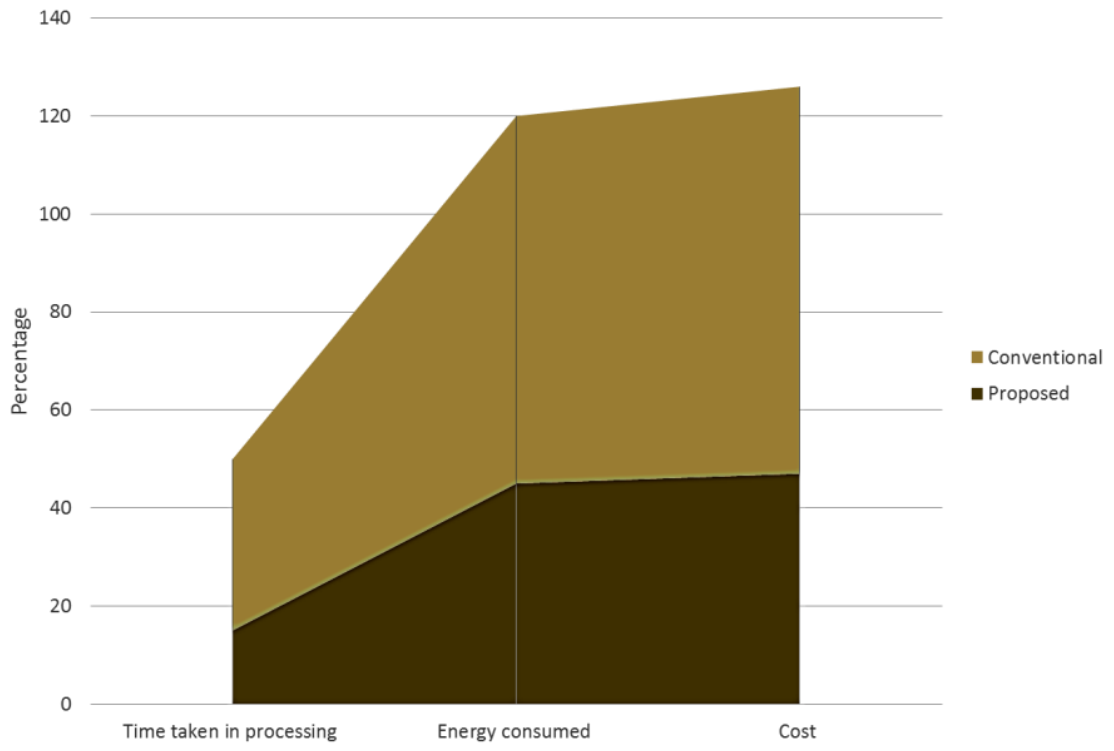

Figure. 4 Time, Energy and Cost Consumed

\section{Conclusion}

The mechanism put forward in the paper aims in reducing the fatalities rate that takes place in the unmanned railway gates in India. The proffered frame work is autonomous and requires a proper maintenance of power to adjust the intervals in time, its functionality has evinced its capacity and its cost efficiency when matched with the conventional railway crossings that are manned. Further the paper scope in developing a completed proof model, with more accuracy and capable of processing extensive range equipping the advanced technologies. 
Journal of Electronics and Informatics (2020)

Vol.02/ No. 01

Pages: $30-37$

http://www.irojournals.com/iroei/

DOI: https://doi.org/10.36548/jei.2020.1.004

\section{References}

[1] Dubey, Alka. "Design and development of an automatic level crossing monitoring system using wireless sensor network in west central railway zone." Sensors \& Transducers 118, no. 7 (2010): 156.

[2] http://www.indianrailways.gov.in/railwayboard/uploads/directorate/finance_budget/Budget_2 015-16/White_Paper-_English.pdf

[3] Michalík, Roman, Aleš Janota, Dušan Nemec, and Marián Hruboš. "Co-operation of the control logic of the t-shape road intersection and the near railway level crossing." Transportation Research Procedia 40 (2019): 1465-1472.

[4] Tjahjono, Tri, Andyka Kusuma, Yodya Yola Pratiwi, and Robby Yudo Purnomo. "Identification determinant variables of the injury severity crashes at road-railway level crossing in Indonesia." Transportation research procedia 37 (2019): 211-218.

[5] Pattanaik, L. N., and Gaurav Yadav. "Decision support model for automated railway level crossing system using fuzzy logic control." Procedia Computer Science 48 (2015): 73-76.

[6] Sharad, S., P. Bagavathi Sivakumar, and V. Ananthanarayanan. "An automated system to mitigate loss of life at unmanned level crossings." Procedia computer science 92 (2016): 404409.

[7] Laapotti, Sirkku. "Comparison of fatal motor vehicle accidents at passive and active railway level crossings in Finland." IATSS research 40, no. 1 (2016): 1-6.

[8] David, Ipinge, and Rituraj Rituraj. "Design of Automated Unmanned Railway Level Crossing System Using Wheel Detector (Sensor) Technology."

[9] Salmon, P.M., Lenné, M.G., Read, G.J., Mulvihill, C.M., Cornelissen, M., Young, K.L., Walker, G.H., Stanton, N.A. and Stevens, N., 2015. Beyond the crossing: a cognitive work analysis of rail level crossing systems. Procedia Manufacturing, 3, pp.2921-2928.

[10] Duraipandian, M., and R. Vinothkanna. "Cloud based Internet of Things for smart connected objects." J. ISMAC 1, no. 02 (2019): 111-119.

[11] Sivaganesan, D. "Efficient Routing Protocol with Collision Avoidance in Vehicular Networks." Journal of Ubiquitous Computing and Communication Technologies (UCCT) 1, no. 02 (2019): 76-86.

[12] Smys, S., Jennifer S. Raj, and Nixon Augustine. "Autonomous Vehicle Navigation in Communication Challenged Environments-A Simulation Approach." (2011).

[13] Raj, Jennifer S., and J. Vijitha Ananthi. "Automation Using Iot in Greenhouse Environment." Journal of Information Technology 1, no. 01 (2019): 38-47.

[14] Manoharan, Samuel. "An Improved Safety Algorithm For Artificial Intelligence Enabled Processors In Self Driving Cars." Journal of Artificial Intelligence 1, no. 02 (2019): 95-104. 